\title{
Ice Particle Impacts on a Moving Wedge
}

\author{
Mario Vargas, Peter M. Struk, Richard E. Kreeger \\ National Aeronautics and Space Administration \\ Glenn Research Center
}

José Palacios,

Pennsylvania State University

Kaushik A. lyer, Robert E. Gold

John Hopkins University Applied Physics Laboratory 


\section{Outline}

- Background

- Objectives

- Approach

- Experiment Set-up

- Data Analysis

- Results

- Conclusions 


\section{Background}

- Aircraft engine ingestion of ice crystals can cause, at operation conditions, permanent or temporary loss of thrust due to ice accretion accumulation and/or shedding in the engine core

- The ice accretion and shedding can affect the performance and/or control of the compressors leading to surging or stalling and in some cases causing permanent damage to the units

- It can cause reduction of the clearance between stationary and moving parts affecting their performance

- The combustor efficiency and stability may also be affected leading to flame outs 


\section{Background}

- Research efforts have been directed to study the physics involved when ice crystals impact on a surface

- The studies aim to identify the main parameters involved, the postimpact particle size and velocity distributions, and the main qualitative features of the impact and fragmentation

- In these studies the ice crystals are modeled with spherical ice particles. This is needed because complete characterization of the ice particles in a natural environment is being studied 


\section{Background}

- The Icing Branch at NASA Glenn and Penn State University have been involved in experimental studies related to ice crystal impacts on internal engine components

- Ice crystal impacts are also important in planetary studies. Planning for the collection of ice crystal samples by instrumentation in spacecraft sent to investigate planetary environments requires knowledge of ice crystal impact physics. This interest brought scientists from the John Hopkins University Applied Physics Laboratory to team with NASA and Penn State University researchers who were studying ice crystal impacts on aircraft engines 


\section{Background}

- Ice particle impacts can be studied in two main configurations: stationary or moving

- In a stationary configuration the ice particles are directed towards a stationary target

- In a moving configuration the target is moving at a high velocity and impacts an ice particle moving at a lower velocity 


\section{Ice Particle Impacts \\ Example of a stationary Flat Plate Experimental Configuration}

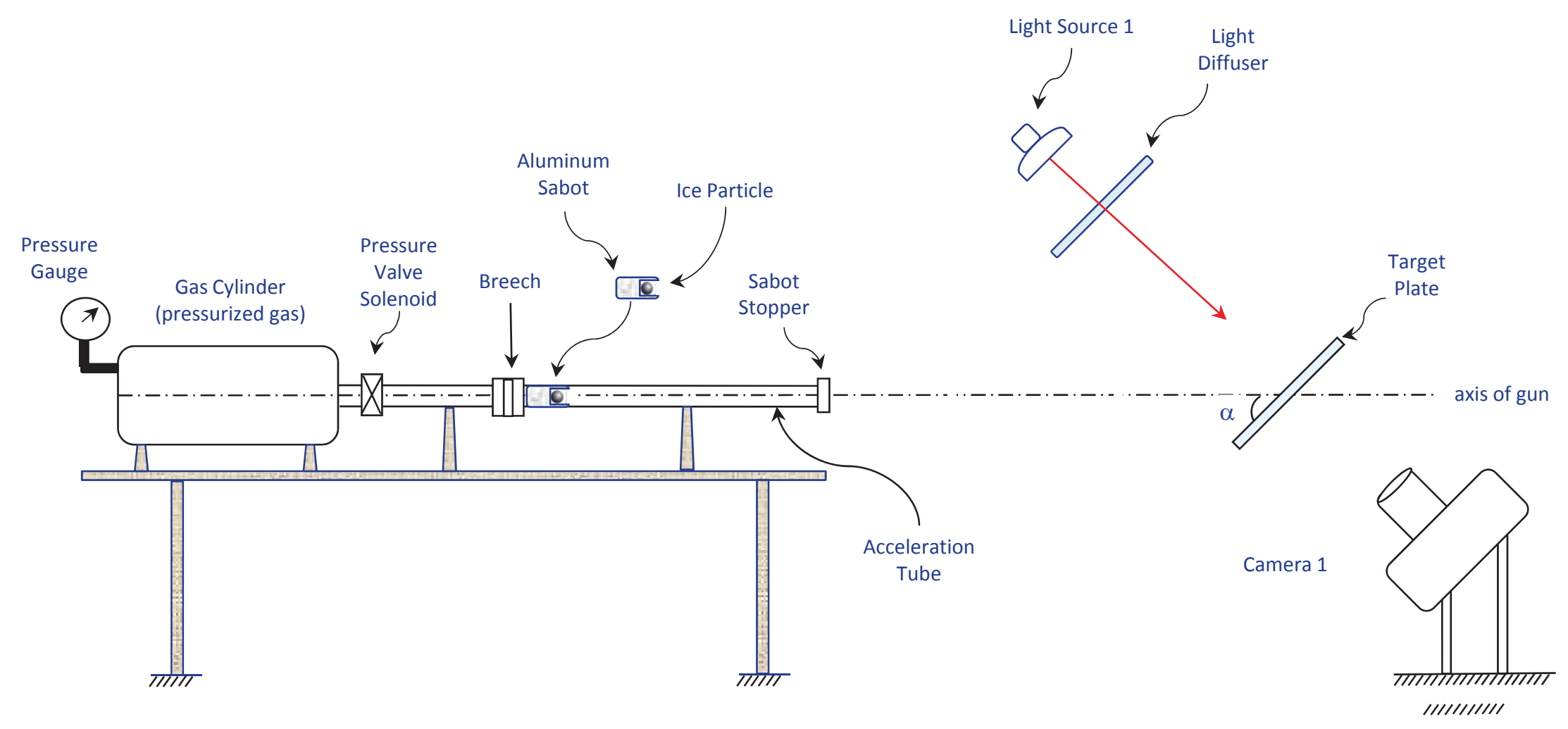




\section{Ice Particle Impacts \\ Example of a Moving Target Experimental Configuration}

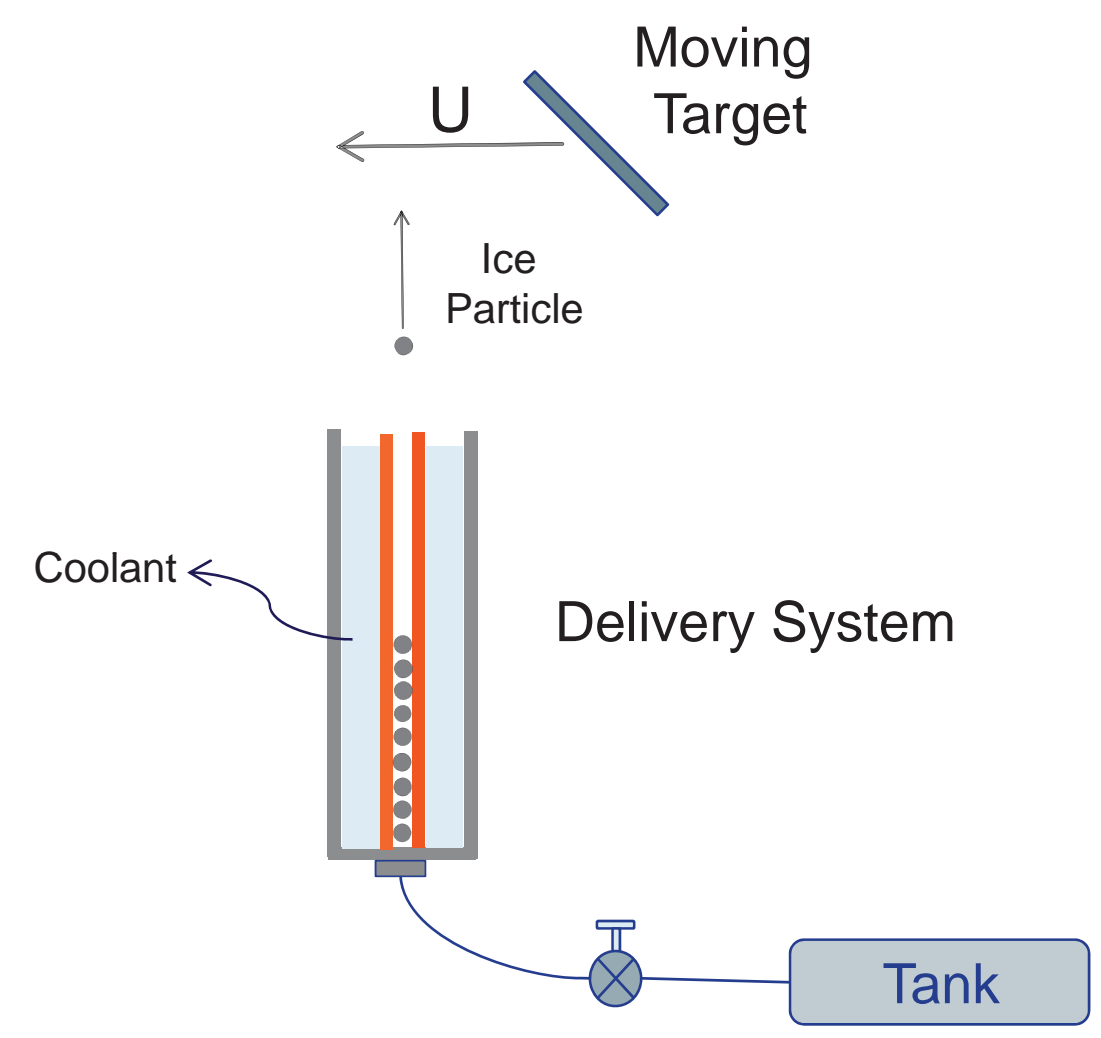




\section{Objectives}

- Develop a methodology to make ice particles and design and fabricate a pressure gun to deliver them

- Modify and instrument the Environment Rotor Test Stand (AERTS) located at Penn State University to be used as the carrier of the moving target

- Determine if the pressure gun and the rotating wedge could be synchronized to consistently obtain ice particle impacts on the target wedge

- Capture the event with high speed imaging and observe the effect of velocity and wedge angle on the post-impact fragment behavior 


\section{Approach}

\section{Conceptual View of Experiment}

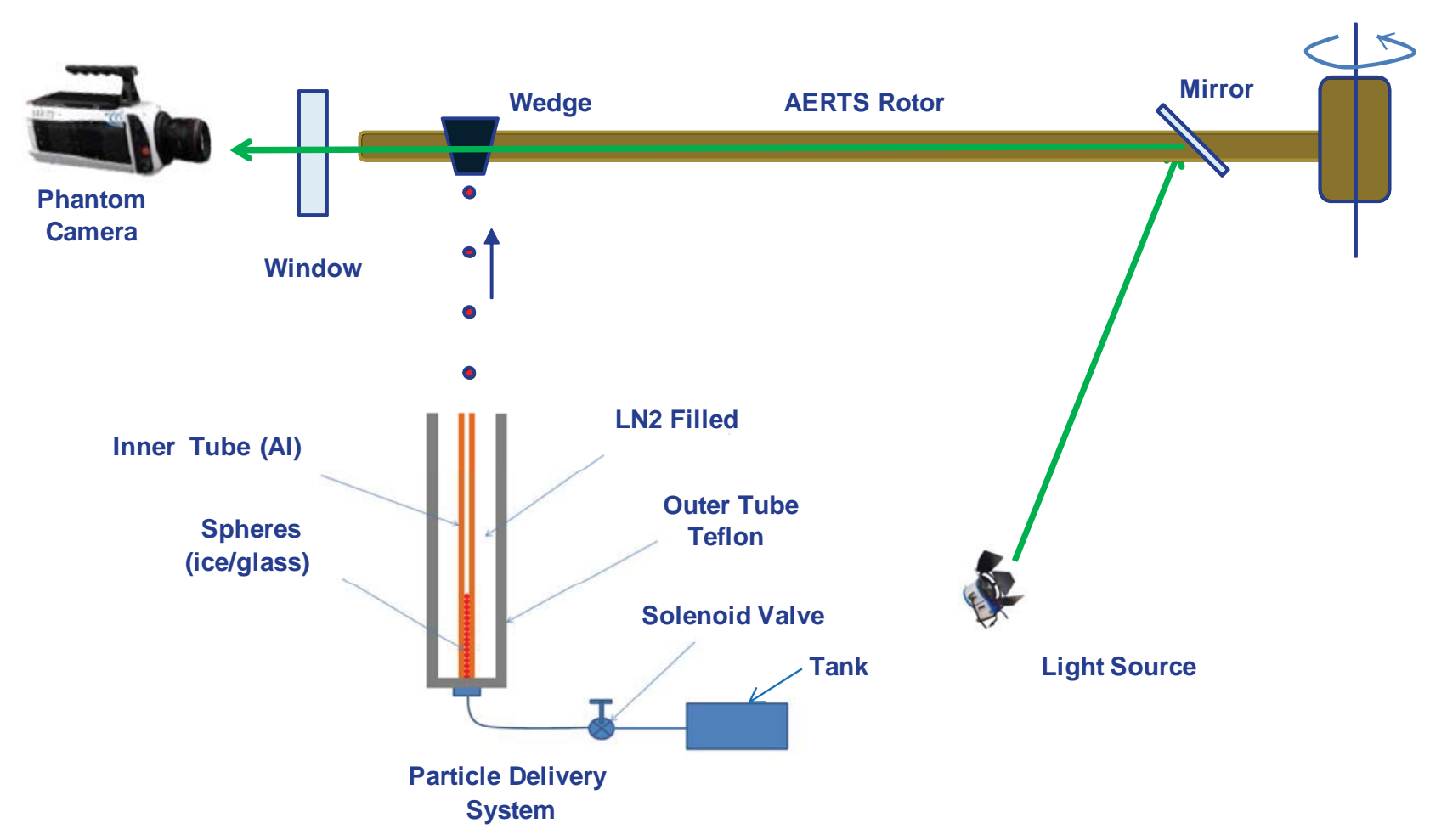




\section{Approach}

Experimental Set-Up at the Environment Rotor Test Stand (AERTS) facility at PSU

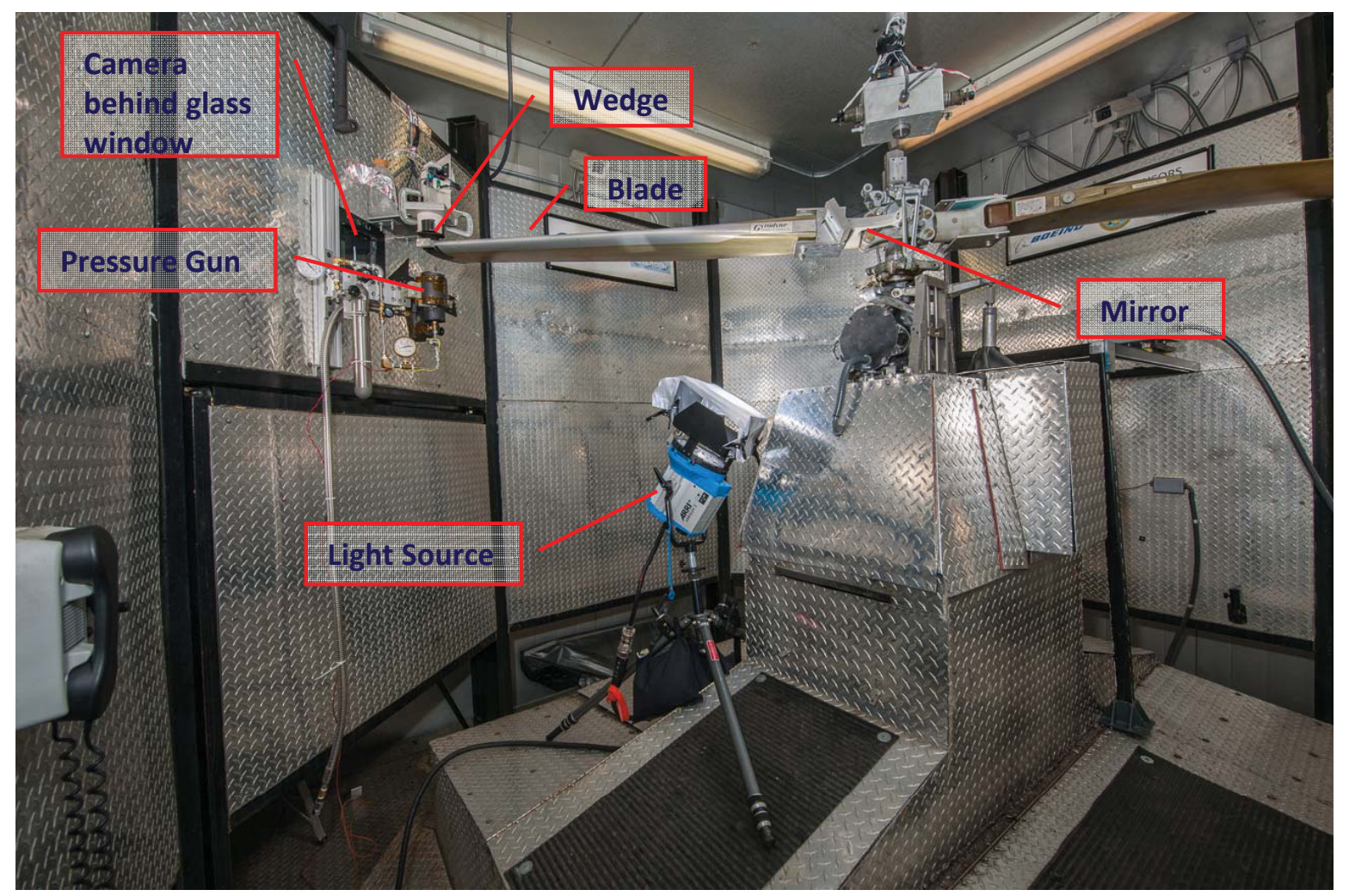




\section{Approach}

\section{Fabrication of Ice Particles}

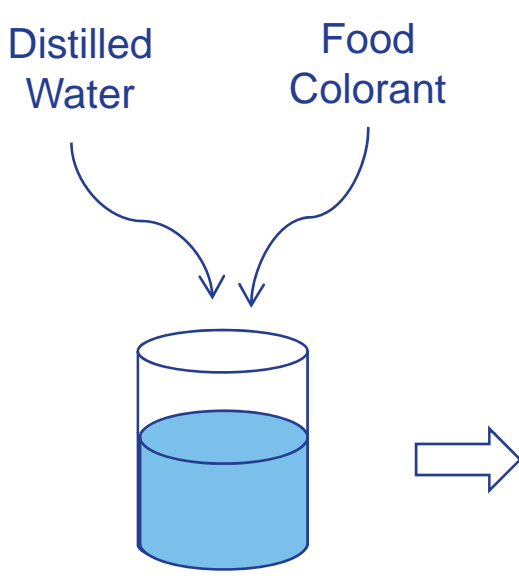

Mix distilled water and food colorant
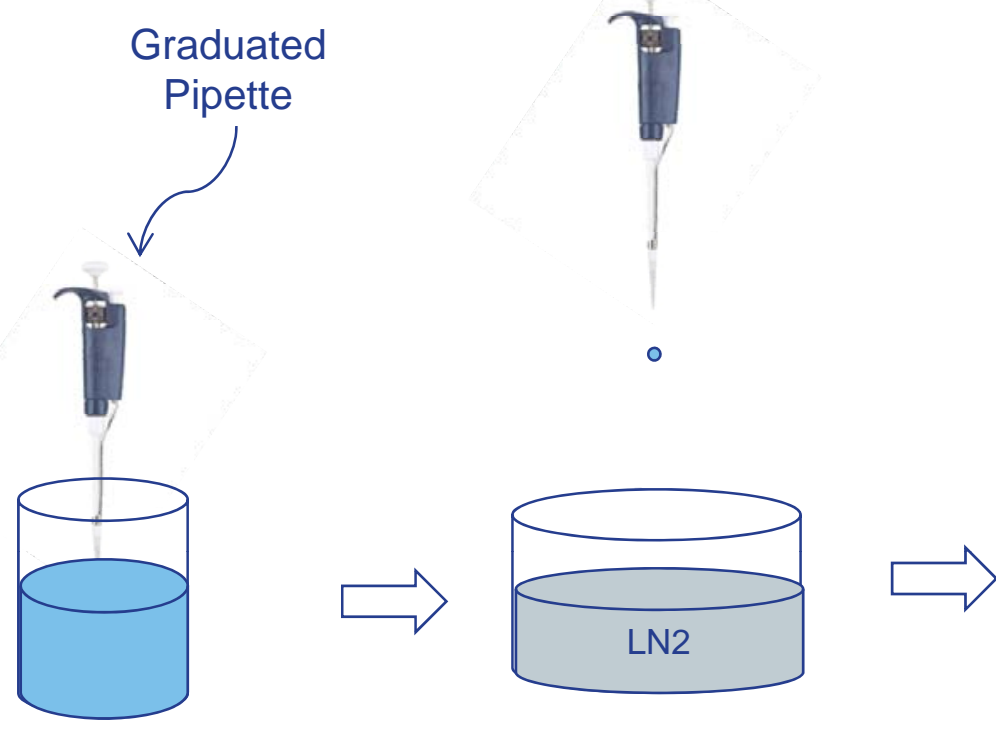

A drop of the liquid water and colorant mix is allowed to fall into liquid nitrogen

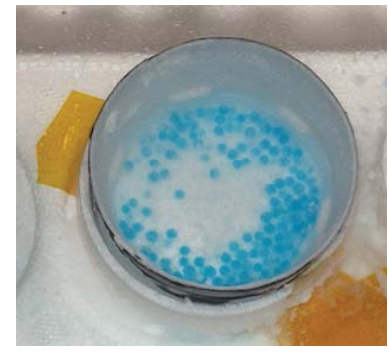

Ice particles collected and ready for the delivery system 


\section{Experimental Set-Up}

\section{Pressure Gun}

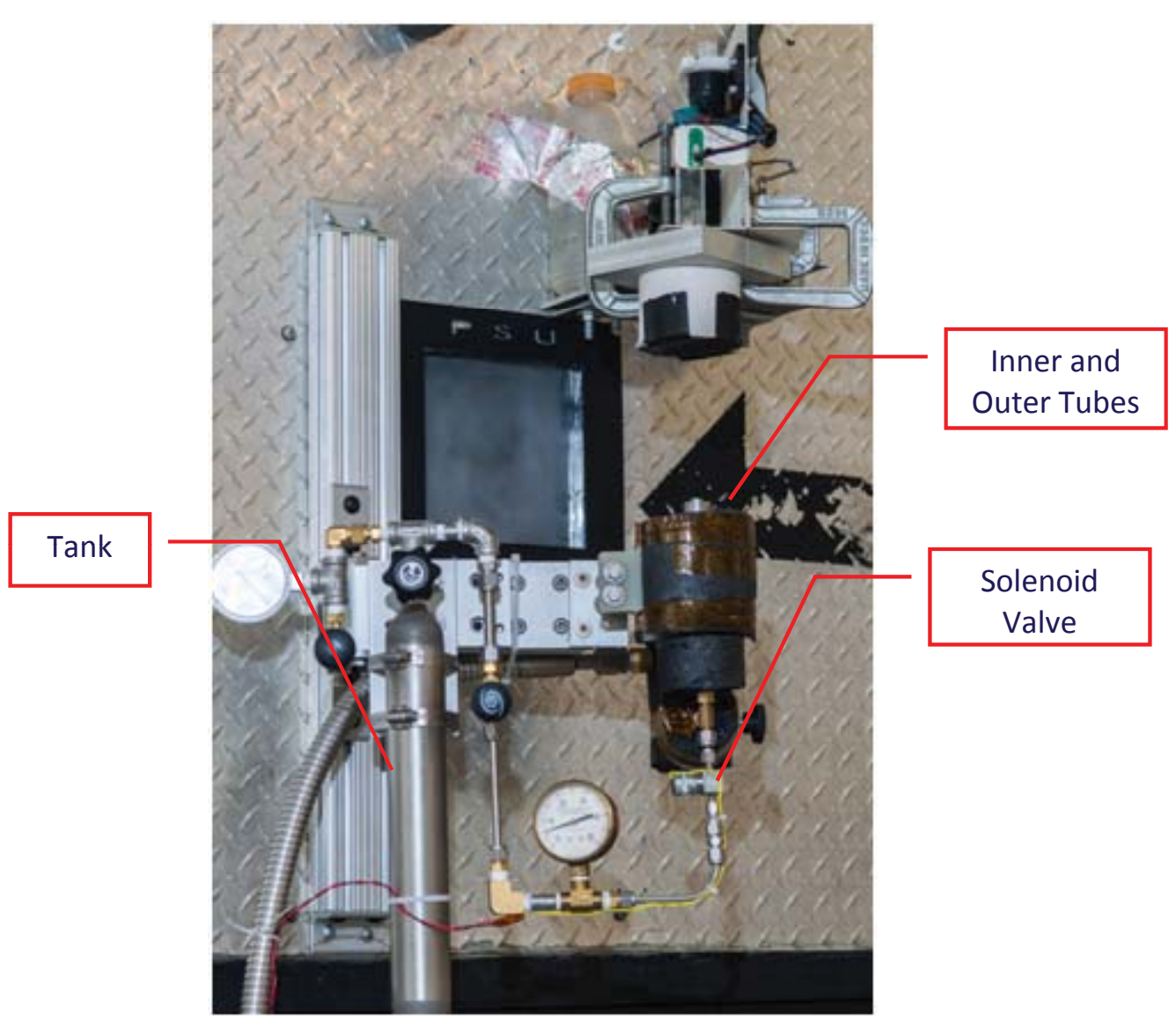




\section{Experimental Set-Up}

Target

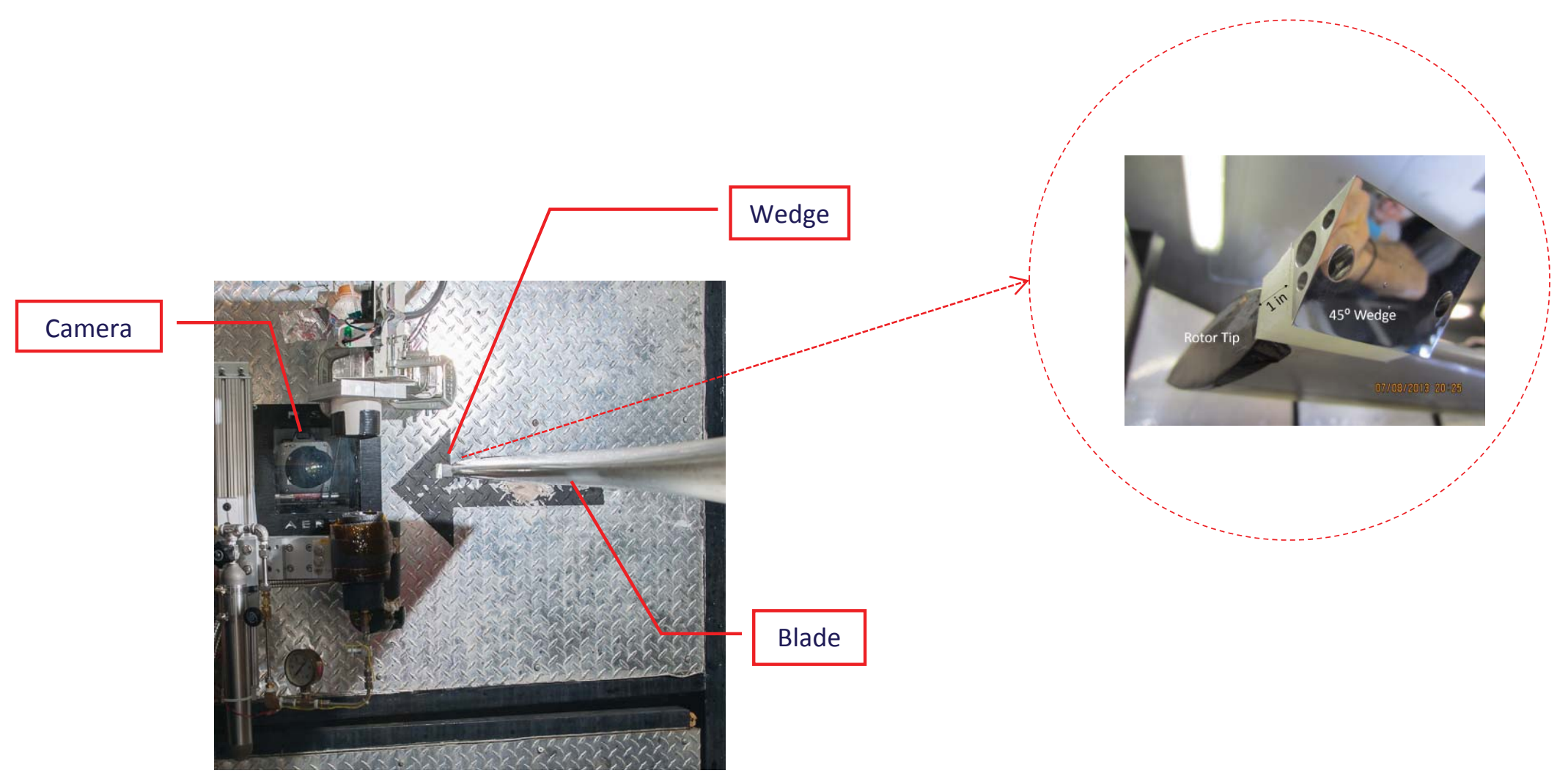




\section{Experimental Set-Up}

\section{Timing Methodology}

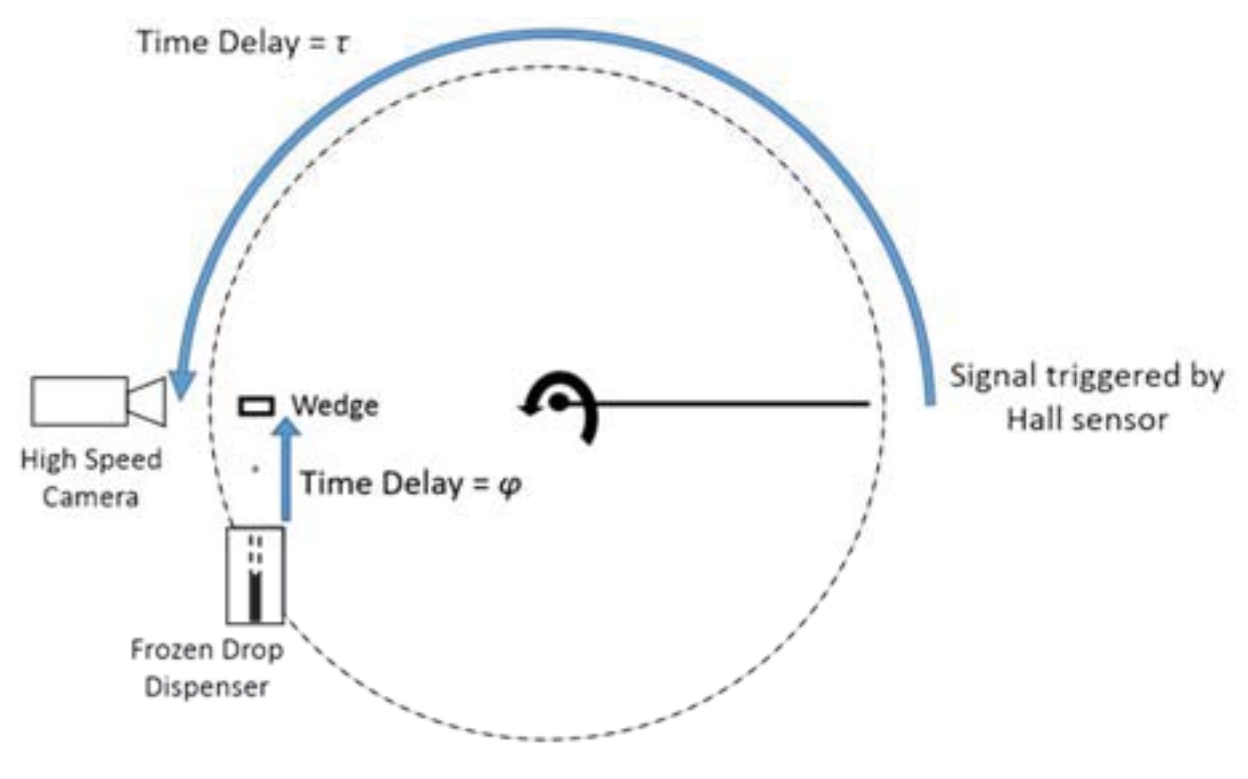

Launch Delay $=\tau-\varphi$ 


\section{Test Matrix}

- A total of 115 runs were completed including runs done to determine the time delays of the pressure gun and the camera

- Wedges of four different angles were used: $0^{\circ}, 30^{\circ}, 45^{\circ}$ and $60^{\circ}$

- The velocities of the wedge were $0,15,20,40,80$ and 120 meters per seconds

- Particles were moving at velocities of 7 to 12 meters per second when they were impacted by the wedge

- The diameter of the particles varied from 1.5 to 3 millimeters.

- The main camera frame rates were 6100 and 6200 frames per second. A reduced number of runs were done at camera frame rates of 9528, 13002 and 21003 frames per second. Typical resolution was 27.5 pixels per millimeter 


\section{Low Velocity Data - Run 7}

$\mathrm{V}_{\text {wedge }}=0 \mathrm{~m} / \mathrm{sec} ;$ Vxparticle $=0 \mathrm{~m} / \mathrm{sec} ;$ Vyparticle $=-3.8 \mathrm{~m} / \mathrm{sec} ;$ Wedge Angle $=60^{\circ} ;$ Diameter $=2.8$ millimeters Camera Frame Rate $=6200 \mathrm{fps}$; Camera Resolution $=27.5$ pixels/millimeter.

Velocities with respect to the wedge $\mathrm{Vn}=-3.3 \mathrm{~m} / \mathrm{sec} ; \mathrm{Vp}=1.9 \mathrm{~m} / \mathrm{sec}$

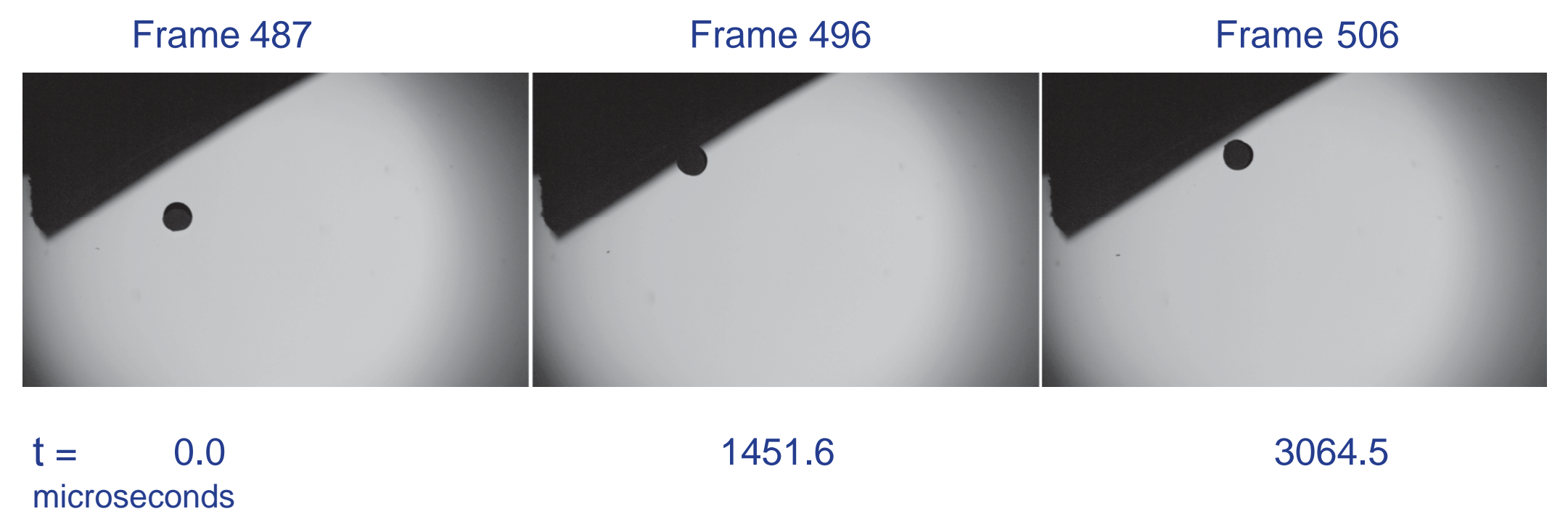




\section{Low Velocity Data - Run 71}

$\mathrm{V}_{\text {wedge }}=0 \mathrm{~m} / \mathrm{sec} ;$ Vxparticle $=0.1 \mathrm{~m} / \mathrm{sec} ;$ Vyparticle $=-5.6 \mathrm{~m} / \mathrm{sec} ;$ Wedge Angle $60^{\circ}$, Diameter $=3.1$ millimeters;

Camera Frame Rate $=6200 \mathrm{fps}$; Camera Resolution $=27.5$ pixels $/$ millimeter.

Velocities with respect to the wedge $\mathrm{Vn}=-4.8 \mathrm{~m} / \mathrm{sec} ; \mathrm{Vp}=2.9 \mathrm{~m} / \mathrm{sec}$

Frame 330

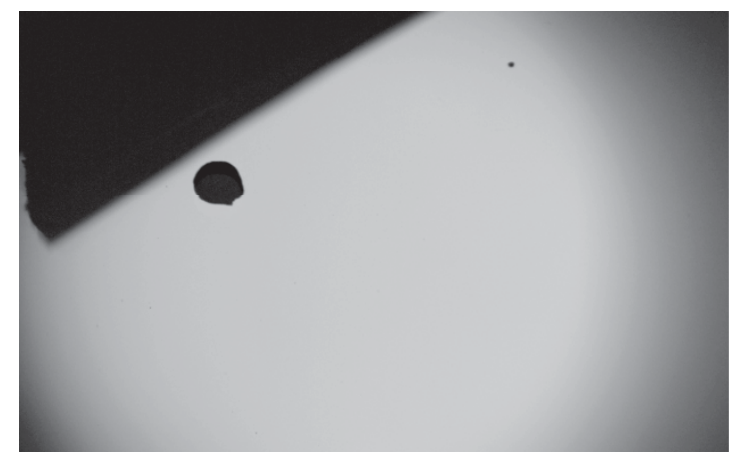

$\mathrm{t}=0.0$

microseconds
Frame 334

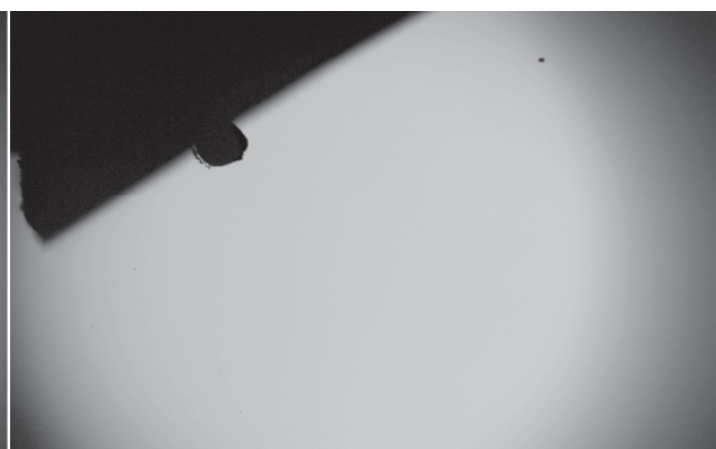

645.2
Frame 358

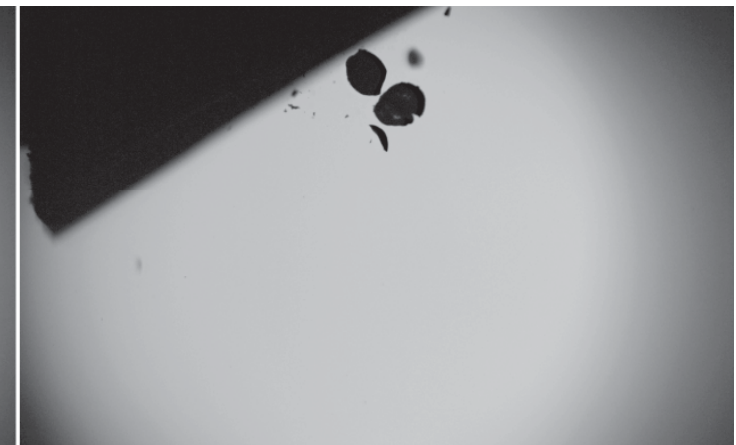

4516.1 


\section{High Velocity Data - Run 85}

$\mathrm{V}_{\text {wedge }}=120 \mathrm{~m} / \mathrm{sec} ; \mathrm{Vx}=0.0 \mathrm{~m} / \mathrm{sec} ;$ Vyparticle $=-9.0 \mathrm{~m} / \mathrm{sec}$; Wedge Angle 30 , Diameter $=2.9$ millimeters;

Camera Frame Rate $=6200 \mathrm{fps}$; Camera Resolution $=27.5$ pixels $/$ millimeter .

Velocities with respect to the wedge $V n=-108.8 \mathrm{~m} / \mathrm{sec} ; \mathrm{Vp}=-52.4 \mathrm{~m} / \mathrm{sec}$

Frame 46

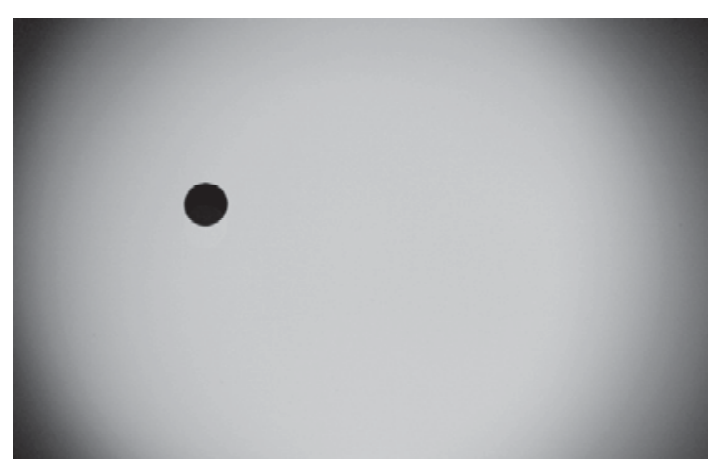

$t=0.0$

microseconds
Frame 47

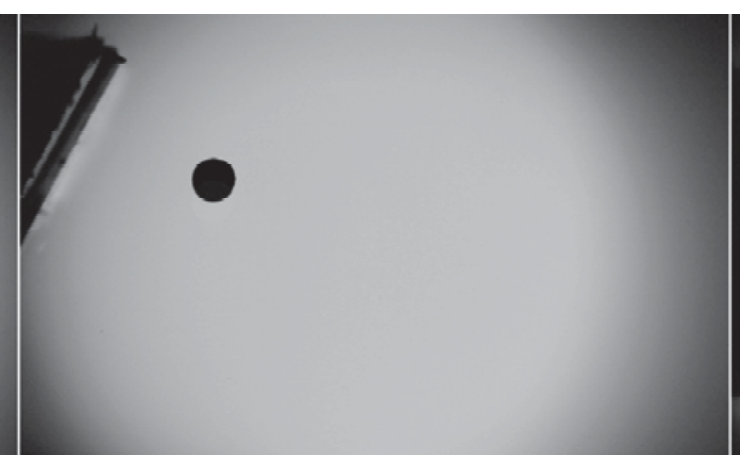

161.3
Frame 48

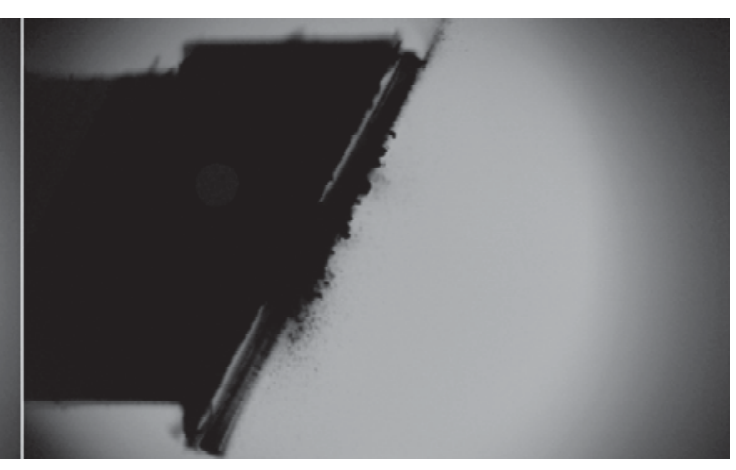

322.6 


\section{Run 23071613 - Ice Particle \#2 Before Impact \\ Overall Data Obtained about the Particle}

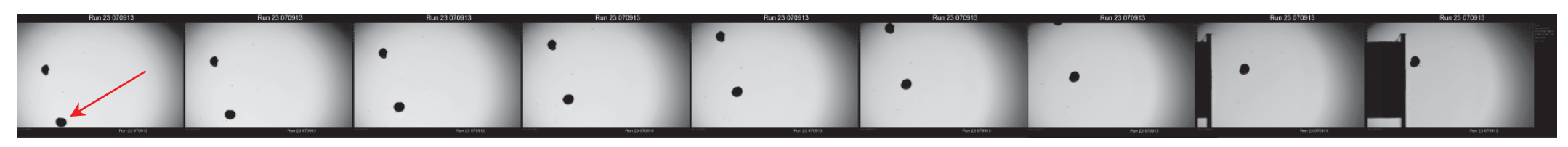

\begin{tabular}{|c|c|c|c|c|c|c|c|c|c|c|c|c|c|}
\hline Frame Number & time & tframe & $\mathrm{x}$ & $\mathrm{y}$ & $\mathrm{x}$ & $\mathrm{y}$ & Area1 & Area2 & Diameter & Pmtr & Ellipsemaj & Ellipsemino & Ellipseangle \\
\hline & tracking & from first & Horiz. Disp. & Vert. Disp. & Horiz. Disp & Vert. Disp. & Area in pix & $\begin{array}{c}\text { Area in } \\
\text { micrometers }\end{array}$ & $\begin{array}{l}\text { Equivalent } \\
\text { Diameter }\end{array}$ & Perimeter & \begin{tabular}{|c|} 
Ellipse \\
Major Axis
\end{tabular} & \begin{tabular}{|c|} 
Ellipse \\
Minor Axis
\end{tabular} & Ellipse Angle \\
\hline & microseconds & microseconds & pixels & pixels & micrometers & micrometers & pixels & micrometers $^{\wedge} 2$ & micrometers & pixels & pixels & pixels & degrees \\
\hline 28 & 0.00 & 4354.84 & 0.00 & 0.00 & 0.00 & \begin{tabular}{|l|}
0.00 \\
\end{tabular} & 4954.00 & 6056530.88 & 2776.94 & 264.11 & 86.28 & 73.31 & -10.82 \\
\hline 29 & 161.29 & 4516.13 & 2.79 & -58.84 & -97.68 & -2057.32 & 5117.00 & 6255807.13 & 2822.26 & 268.11 & 86.59 & 75.43 & -1.50 \\
\hline 30 & 322.58 & 4677.42 & 5.28 & -117.19 & -184.67 & -4097.48 & 5259.00 & 6429409.75 & 2861.15 & 286.01 & 86.76 & 77.53 & 12.79 \\
\hline 31 & 483.87 & 4838.71 & 7.79 & -175.68 & -272.40 & -6142.48 & 5329.00 & 6514988.51 & 2880.13 & 273.52 & 87.18 & 77.98 & 21.13 \\
\hline 32 & 645.16 & 5000.00 & 10.12 & -233.47 & -353.73 & -8163.26 & 5390.00 & 6589564.28 & 2896.57 & 276.94 & 87.68 & 78.40 & 31.59 \\
\hline 33 & 806.45 & 5161.29 & 12.63 & -291.07 & -441.59 & -10177.28 & 5415.00 & 6620128.12 & 2903.28 & 277.52 & 88.36 & 78.18 & 41.90 \\
\hline 34 & 967.74 & 5322.58 & 15.41 & -348.47 & -538.89 & -12184.38 & 5422.00 & 6628686.00 & 2905.15 & 279.42 & 89.07 & 77.74 & 50.76 \\
\hline 35 & 1129.03 & 5483.87 & 18.66 & -405.63 & -652.32 & -14182.74 & 5418.00 & 6623795.78 & 2904.08 & 279.18 & 89.94 & 77.01 & 59.30 \\
\hline 36 & 1290.32 & 5645.16 & 22.41 & -462.84 & -783.43 & -16183.25 & 5298.00 & 6477089.34 & 2871.74 & 277.76 & 90.47 & 75.05 & 67.34 \\
\hline
\end{tabular}




\section{Run 23071613 - Ice Particle \#2 Before Impact}

Vertical Velocity with respect to the Laboratory

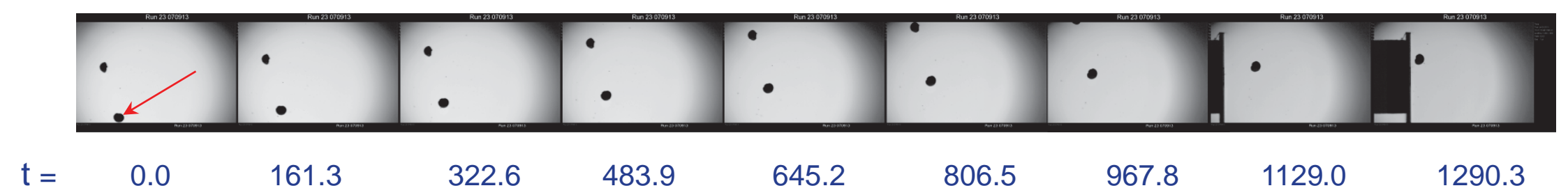

microseconds
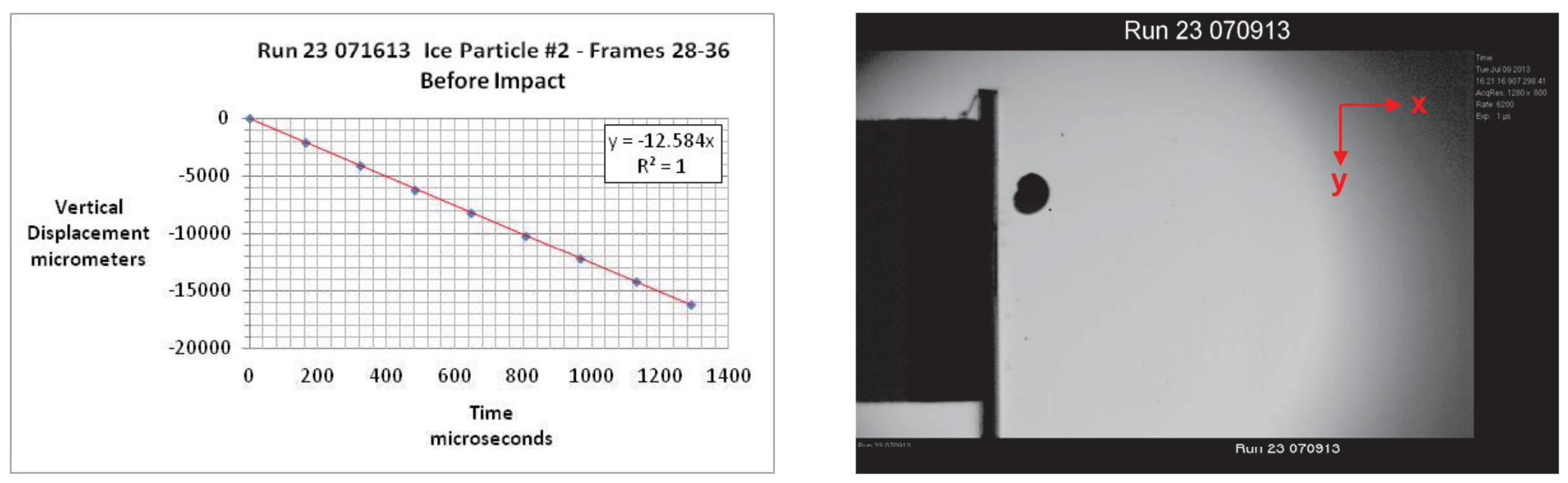

$$
V_{y}=-12.6 \mathrm{~m} / \mathrm{sec}
$$




\section{Data Analysis Main Focus}

- Studies by Guégan et al. and Pan and Render on the impact of hail-size ice particles showed very high velocities for the first ejected fragments during impact. The velocity of those first ejected fragments was higher than the approaching ice particle velocity before impact

- Scale difference between ice particles used in the experiment and hail stones used in past studies was 4 times or larger

- The main focus of the data analysis was to measure the velocity of the edge of the fragment cloud to determine if at the reduced size of the ice particles tested, the initial ejected fragments exhibited the same velocity behavior

- Additional general qualitative observations were recorded 


\section{High Velocity Data - Run 85}

$\mathrm{V}_{\text {wedge }}=120 \mathrm{~m} / \mathrm{sec} ; \mathrm{Vx}=0.0 \mathrm{~m} / \mathrm{sec} ;$ Vyparticle $=-9.0 \mathrm{~m} / \mathrm{sec}$; Wedge Angle 30 , Diameter $=2.9$ millimeters;

Camera Frame Rate $=6200 \mathrm{fps}$; Camera Resolution $=27.5$ pixels $/$ millimeter .

Velocities with respect to the wedge $V n=-108.8 \mathrm{~m} / \mathrm{sec} ; \mathrm{Vp}=-52.4 \mathrm{~m} / \mathrm{sec}$

Frame 46

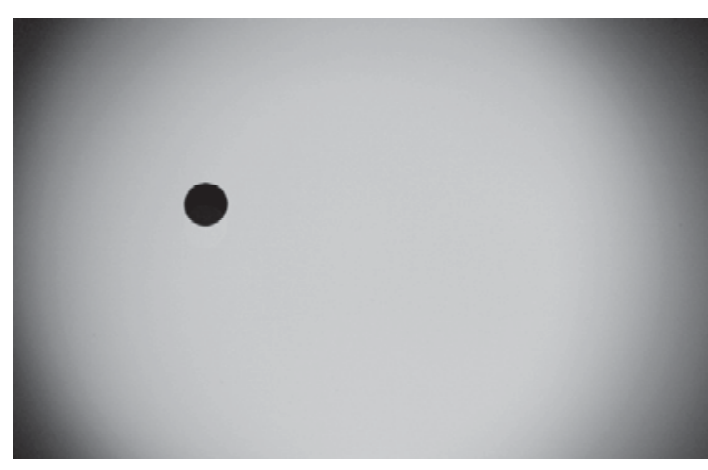

$t=0.0$

microseconds
Frame 47

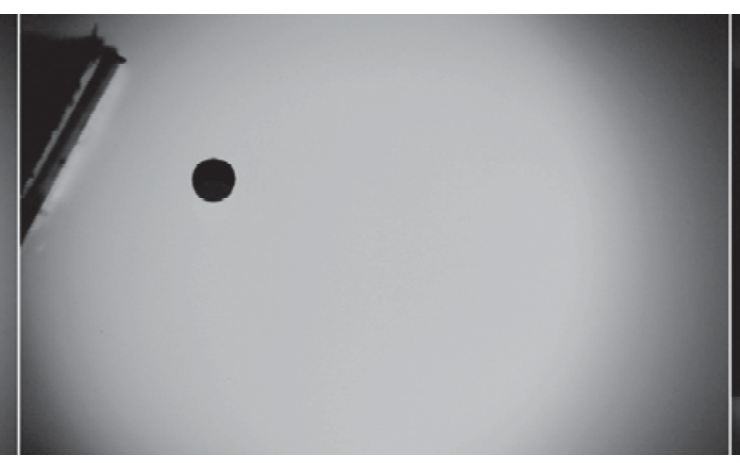

161.3
Frame 48

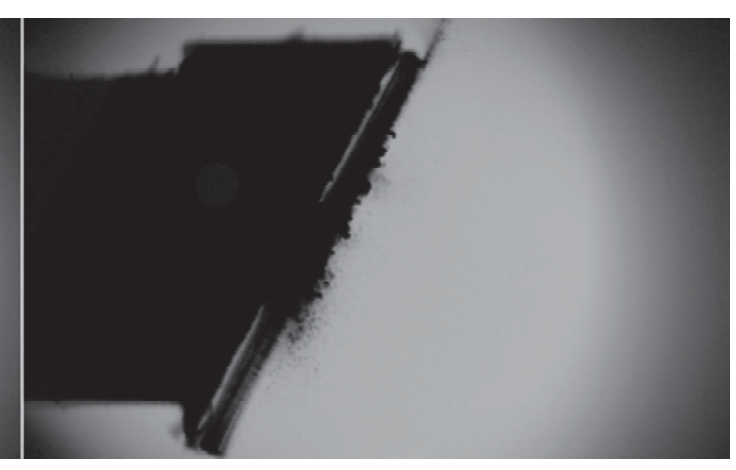

322.6 


\section{Data Analysis}

\section{Cloud Velocity Measurement Methodology}

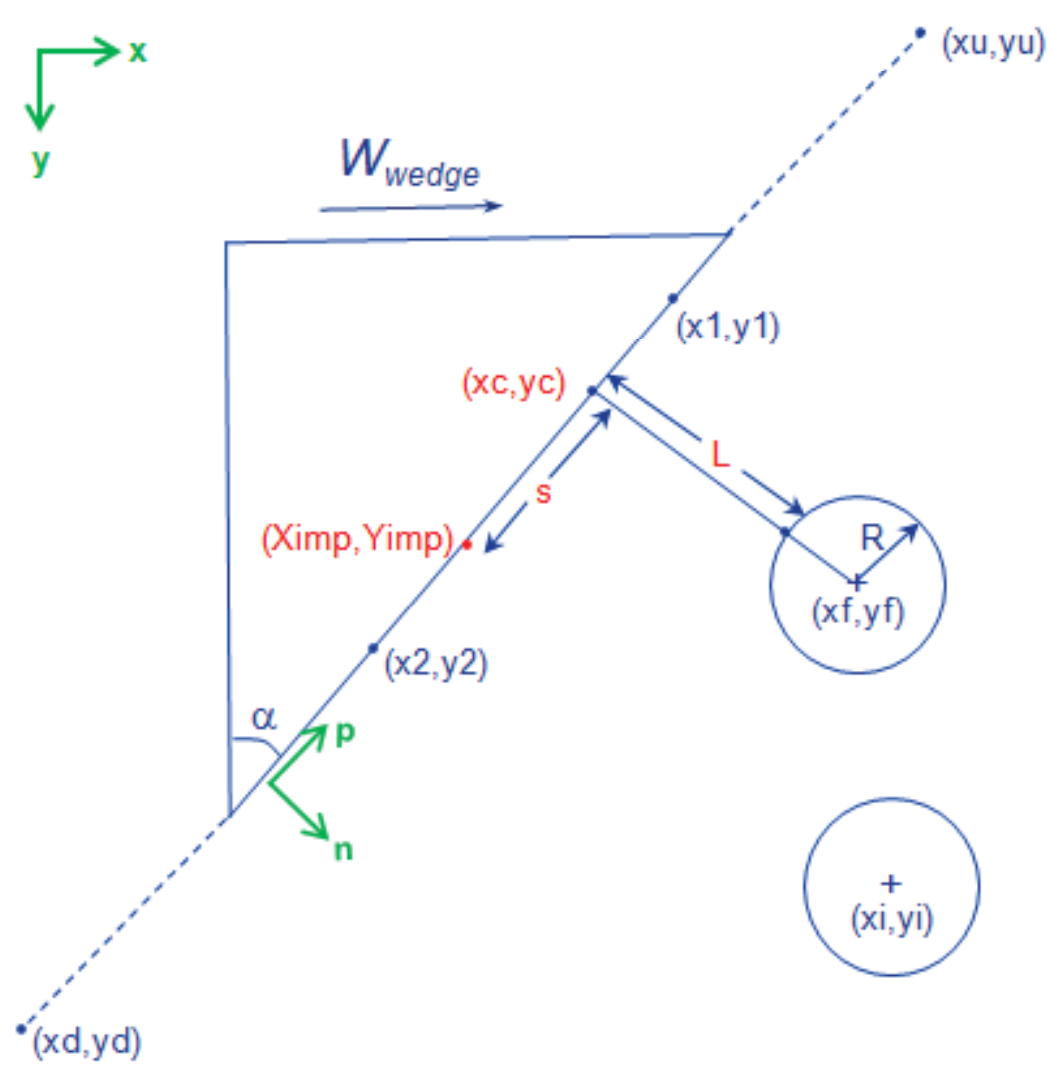

Inp ut Parameters

(xi,yi), (xf,yf), (x1,y1), (x2,y2), (xd,yd), (xu,yu),

$\mathrm{R}, \alpha$, res, fmr

ת

$\begin{array}{cc}\vec{V}_{x y}=u \vec{i}+v \vec{j} & u=\frac{(x f-x i)^{*} \text { fmr }}{1000^{*} \text { resolution }} \quad v=\frac{(y f-y i) * \text { fmr }}{1000^{*} \text { resolution }} \\ \vec{V}_{n p}=\left(V_{n} \vec{n}+V_{p} \vec{p}\right) & V_{n}=\left(v^{*} \sin \alpha+u^{*} \cos \alpha-\left|W_{\text {wedge }}\right| * \cos \alpha\right) \vec{n} \\ V_{p}=\left(u^{*} \sin \alpha-v^{*} \cos \alpha-\left|W_{\text {weags }}\right| * \sin \alpha\right) \vec{p}\end{array}$

$(x c, y c), L$

$t=L\left(\operatorname{abs}\left(V_{n}\right)\right), \quad s=V_{p}{ }^{*} t$

ת

Ximp $=x c+s^{*} \sin (\alpha)$

Yimp $=y c-s^{*} \cos (\alpha)$

$\Omega$

$$
\begin{gathered}
V_{\text {cloud-up }}=\frac{\sqrt{(x u-x i m p)^{2}+(y u-y i m p)^{2}}-R}{(1 / \text { fimr })-t} \\
V_{\text {cloud-down }}=\frac{\sqrt{(x d-x i m p)^{2}+(y d-y i m p)^{2}}-R}{(1 / f m r)-t}
\end{gathered}
$$




\section{Results - Run 85}

$V_{\text {wedge }}=120 \mathrm{~m} / \mathrm{sec} ; \mathrm{Vx}=0.0 \mathrm{~m} / \mathrm{sec} ;$ Vyparticle $=-9.0 \mathrm{~m} / \mathrm{sec}$; Wedge Angle $30^{\circ}$, Diameter $=2.9$ millimeters;

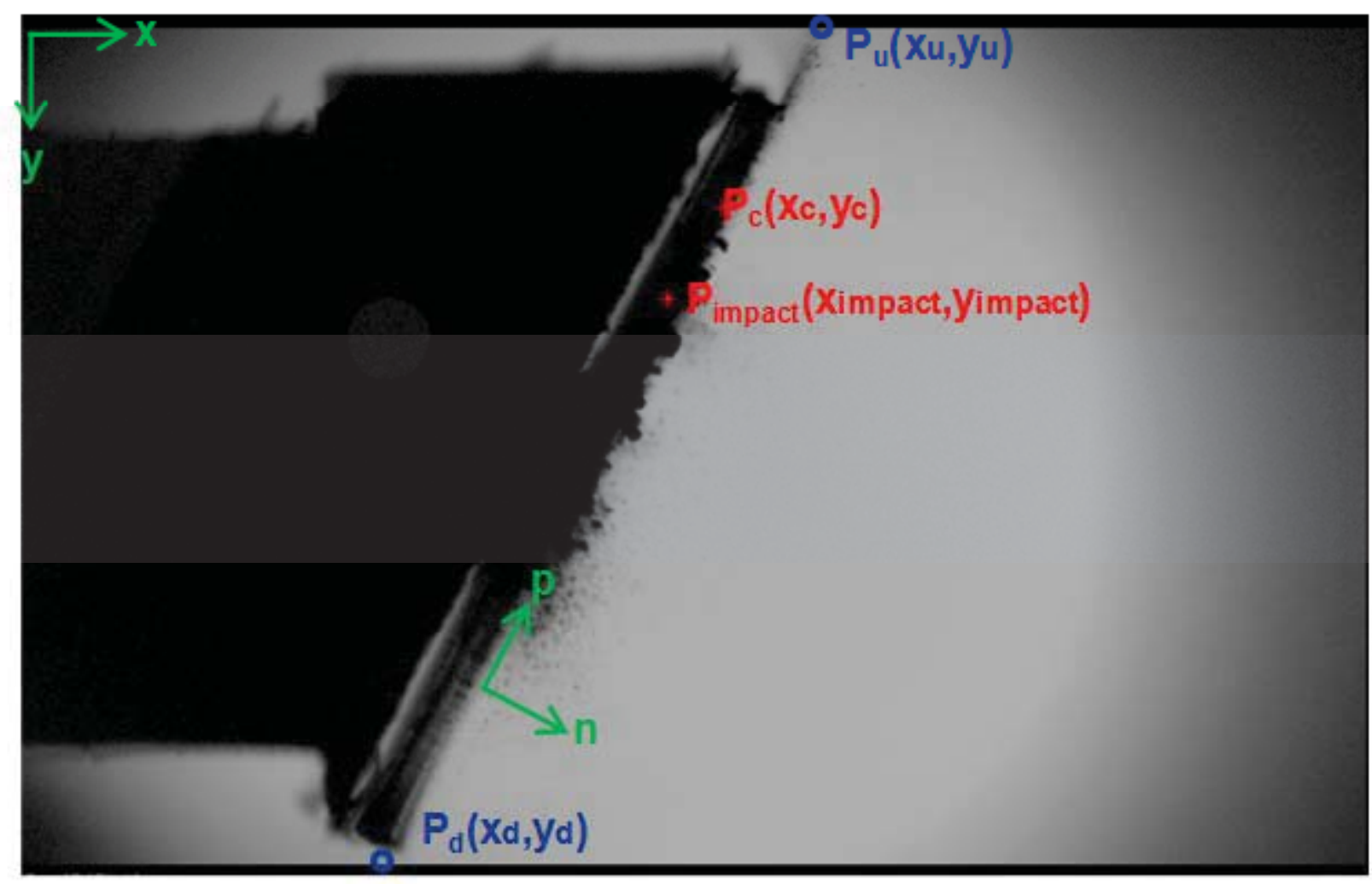

\begin{tabular}{|c|c|c|c|c|}
\hline ximpact & yimpact & Cloud Velocity Down & Cloud Velocity Up & Wedge Velocity \\
\hline Pixels & Pixels & $\mathrm{m} / \mathrm{sec}$ & $\mathrm{m} / \mathrm{sec}$ & $\mathrm{m} / \mathrm{sec}$ \\
\hline 82.2 & 259.0 & -240.2 & 117.8 & 120.4 \\
\hline
\end{tabular}




\section{Results}

Selecting the Edge Points of the Cloud

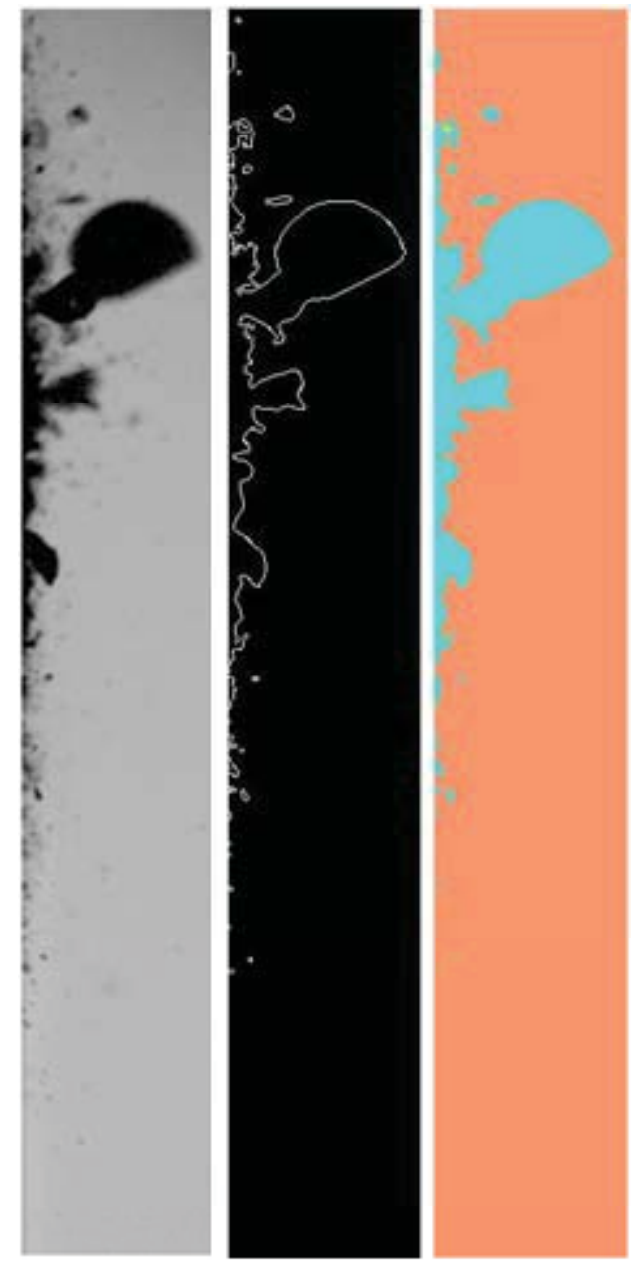




\section{Results - Run 96}

$V_{\text {wedge }}=120 \mathrm{~m} / \mathrm{sec} ;$ Vyparticle $=-10.3 \mathrm{~m} / \mathrm{sec} ;$ Wedge Angle $0^{\circ}$, Diameter $=1.7$ millimeters;

Frame 44

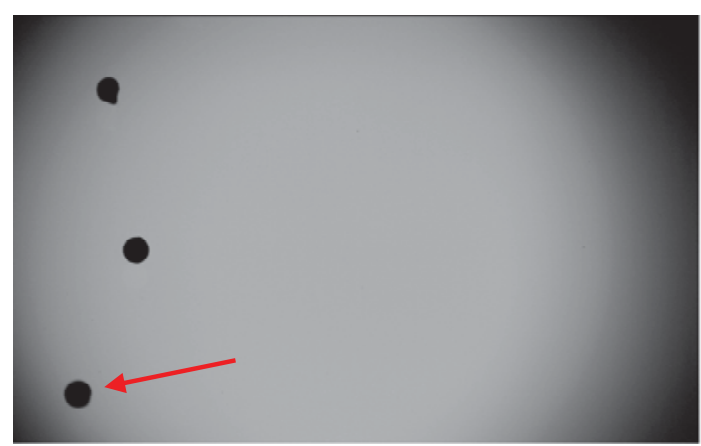

$\mathrm{t}=$

0.0

microseconds
Frame 45

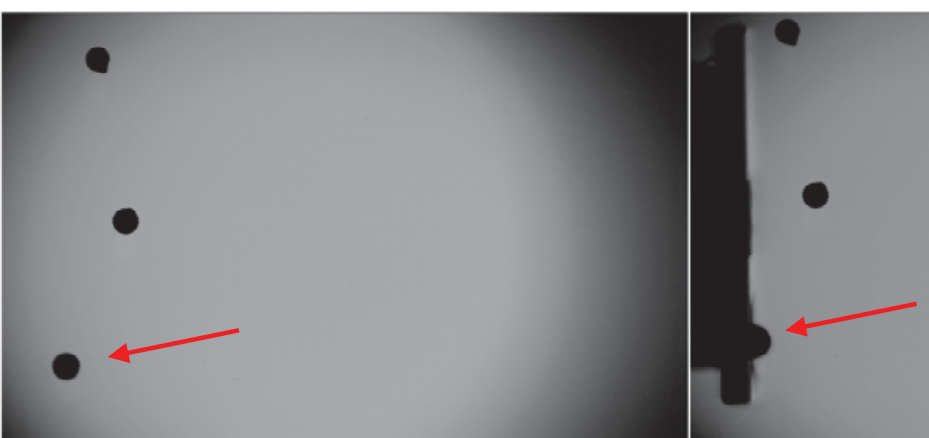

163.9
Frame 46

327.9 


\section{Results - Run 96}

$\mathrm{V}_{\text {wedge }}=120 \mathrm{~m} / \mathrm{sec} ;$ Vyparticle $=-10.3 \mathrm{~m} / \mathrm{sec}$; Wedge Angle $0^{\circ}$, Diameter $=1.7$ millimeters

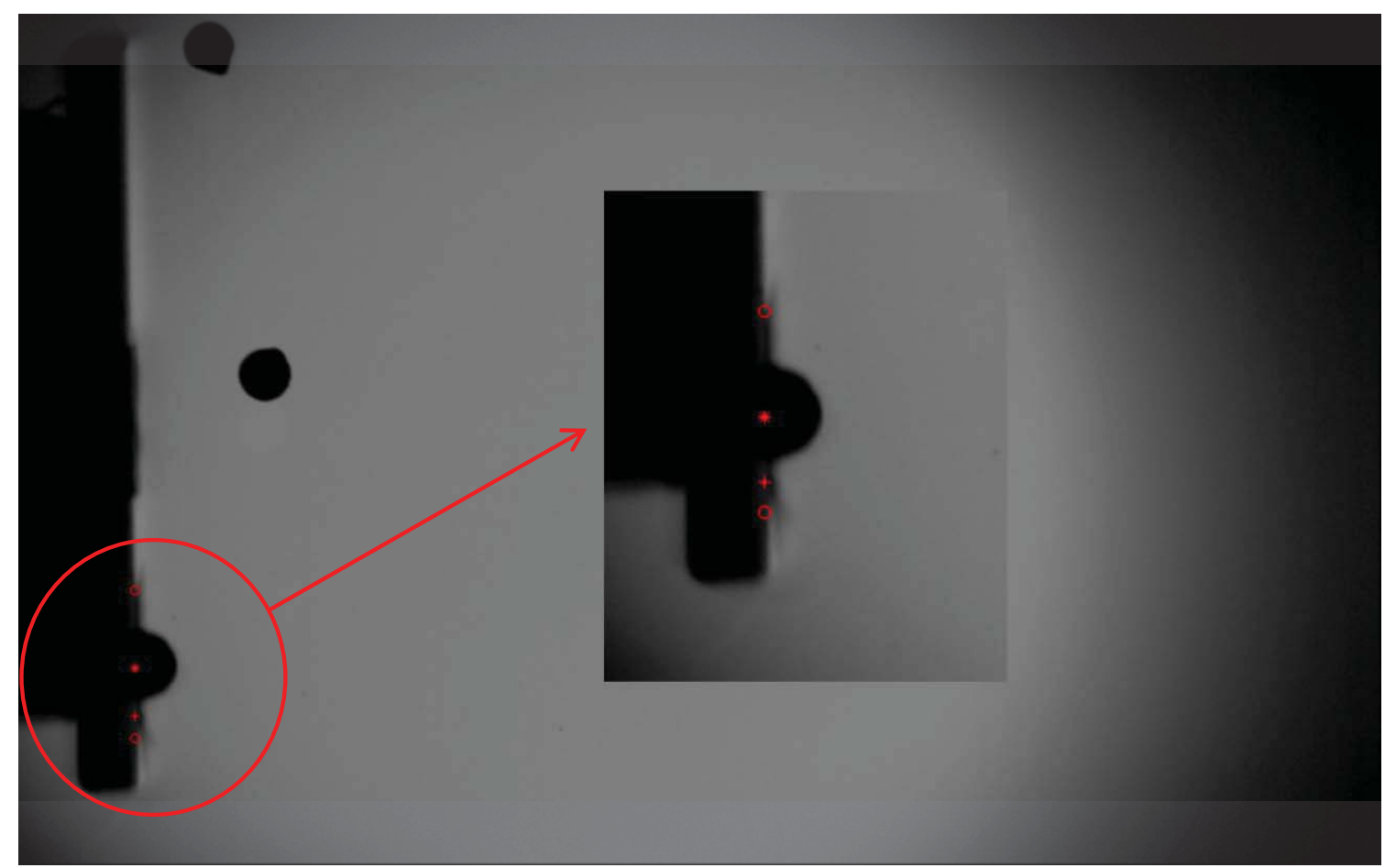

\begin{tabular}{|c|c|c|c|c|}
\hline ximpact & yimpact & Cloud Velocity Down & Cloud Velocity Up & Wedge Velocity \\
\hline Pixels & Pixels & $\mathrm{m} / \mathrm{sec}$ & $\mathrm{m} / \mathrm{sec}$ & $\mathrm{m} / \mathrm{sec}$ \\
\hline-430.0 & 617.9 & -326.3 & 388.1 & 120.2 \\
\hline
\end{tabular}




\section{Additional General Observations}

- Fragment size was found to decrease with the impact kinetic energy. This can be expected because the higher the impact energy, the more fracture cracks are created in the particle

- Guégan et al. and Pan and Render, when studying impact of hailstones at high velocities, observed a very shallow angle at which the particle fragments move in a direction perpendicular to the impact surface. Angles of less than $2^{\circ}$ were observed. Particle fragments bounce very little; they spread over the surface

- To verify this with the smaller size ice particles used in the present experiment, the distance of fragment rebound was measured normal to the wedge surface in the first post-impact image. At the lower velocities the fragments can rebound a large distance from the wedge surface. As the velocity is increased, the rebound distance decreases and at $120 \mathrm{~m} / \mathrm{sec}$ it was measured to be less than 6 millimeters. This agrees with what was observed by Guégan et al. and Pan and Render 


\section{Conclusions}

- A rotating wedge and an ice particle shot from a pressure gun can be timed so that an impact on the target can be obtained with some degree of repeatability and captured with high speed imaging. The experimental configuration allows the study of ice particle impacts on a moving surface

- The data showed that the velocities of the first ejected fragments that formed the edge of the cloud were higher than the approaching ice particle velocity before impact. This result agrees with work done by researchers studying the impact of hailstones on flat plate targets

- $\quad$ At the higher velocity tested, 120 meters per second, the fragments after impact tended to have a low bounce normal to the wedge, compared to the motion of the fragments along the surface of the wedge. This also agrees with previous observations from studies on hailstone impacts on a flat surface

- The results of the work presented here will help in the design of future experiments of ice particle impacts on a moving surface. The experiments are needed to understand the physics involved in the impact of ice crystals on moving elements in turbofan engines which is one of the current main areas of engine icing studies 


\section{END OF PRESENTATION}

